\title{
Robotic endoscopic excision of accessory mitral leaflet
}

\author{
Douglas A. Murphy, MD, ${ }^{a}$ John J. Byrne, MD, and Hector A. Malave, MD, ${ }^{\mathrm{c}}$ Atlanta, Ga
}

A ccessory mitral valve is an uncommon cause of left ventricular outflow tract obstruction in the adult patient. ${ }^{1}$ Excisional therapy has traditionally been performed through the proximal aorta by using a median sternotomy. We report the excision of an obstructive accessory mitral leaflet through the left atrium using a right chest endoscopic approach with the da Vinci Robotic System (Intuitive Surgical, Sunnyvale, Calif).

\section{Clinical Summary}

A 43-year-old man presented with dyspnea on exertion of 1 years' duration. Examination revealed a body mass index of $36.7 \mathrm{~kg} / \mathrm{m}^{2}$ and a systolic cardiac murmur. Transesophageal echocardiography demonstrated a membranous structure in the left ventricular outflow tract with a parachute action during systole. Chordal attachment suggested this membranous structure was an accessory mitral leaflet. Peak systolic gradient across the membrane measured 45 $\mathrm{mm} \mathrm{Hg}$. Right and left cardiac catheterization confirmed the echocardiographic findings and showed normal coronary arteries. Surgical excision was undertaken to relieve symptoms.

At the time of the operation, the heart was approached endoscopically through 4 ports in the third, fourth, and sixth intercostal spaces of the right lateral chest (Figure 1). Intermittent insufflation with carbon dioxide was used to create working space for pericardiotomy and traction sutures. Cardiopulmonary bypass, endoaortic balloon occlusion, and antegrade cardioplegia were achieved through the femoral vessels, and pulmonary artery venting and retrograde cardioplegia administration were achieved through the right internal jugular vein by using the Port Access System (Cardiovations, Somerville, NJ). The left atrium was entered immediately anterior to the right pulmonary veins, and the atrial septum was retracted anteriorly to expose the mitral valve. The anterior mitral leaflet was partially detached to visualize the left ventricular outflow tract. An accessory mitral leaflet with chordal tissue attachment was then excised with the robotic instruments, assisted by a handheld shafted forceps inserted through the service port (Figure 2). The anterior mitral leaflet was patched with glutaraldehyde-treated autologous pericardium to prevent leaflet shortening with repair. A vent through the closed left atriotomy and across the mitral valve

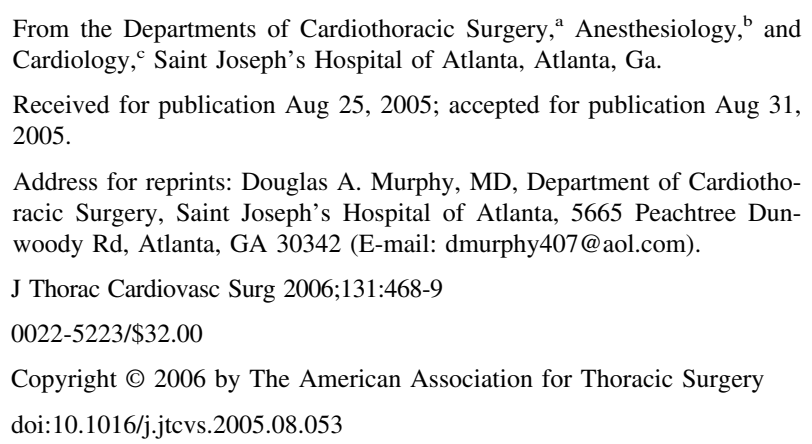

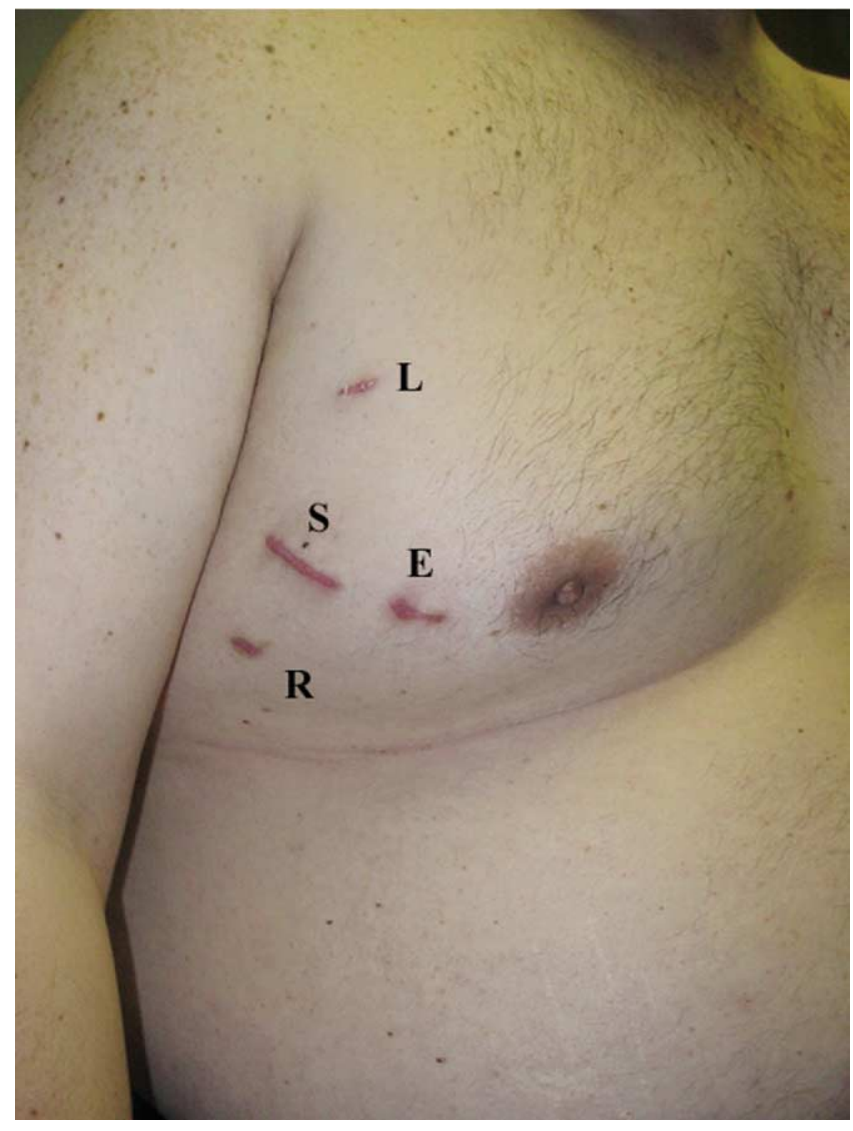

Figure 1. Endoscopic ports. $R$, Robotic right arm; $L$, robotic left arm; $E$, robotic endoscope; $S$, service port.

was used to ensure air removal. Aortic occlusion time was 77 minutes. Postoperative echocardiography demonstrated a peak systolic left ventricular gradient of less than $7 \mathrm{~mm} \mathrm{Hg}$ and normal mitral valve function. The patient was discharged on postoperative day 3 after an uncomplicated recovery and is in New York Heart Association class 1 at 6 weeks after the operation.

\section{Discussion}

Endoscopic approach to the left ventricular outflow tract through the right chest has been previously described for septal myomectomy and fibroelastoma of the aortic valve by using 2-dimensional videoscopy and handheld shafted instruments. ${ }^{2,3}$ Excellent visualization of this area is afforded by partial detachment of the anterior mitral leaflet, leaving the commissural attachments intact to maintain proper orientation. Reconstruction of the anterior leaflet with autologous pericardium is supported by experience with rheumatic valve repair. ${ }^{4}$ Although an endoscopic technique is the least inva- 




Figure 2. Excision of accessory mitral leaflet (AML) with assistance of handheld shafted instrument (HSI).

sive surgical method to approach intracardiac lesions, such as the accessory mitral valve described here, it can be technically challenging. The use of the da Vinci system offers a stable instrument platform coupled with stereoscopic vision at surgical sites deep within the thorax. Surgical manipulations with the mechanical robotic instruments are facilitated by handheld shafted instruments inserted by the patient-side assistant through an adjacent service port. Placing the service port between the instrument arms and lateral to the endoscope port allows both the patient-side assistant and the console surgeon to work simultaneously at the intracardiac operative site. The da Vinci Robotic System might facilitate an endoscopic approach to lesions of the left ventricular outflow tract.

\section{References}

1. Aoka Y, Ishizuka N, Sakomura Y, Nagashima H, Kawana M, Kawai A, et al. Accessory mitral valve tissue causing severe left ventricular outflow tract obstruction in an adult. Ann Thorac Surg. 2004;77:713-5.

2. Casselman F, Vanermen H. Idiopathic hypertrophic subaortic stenosis can be treated endoscopically. J Thorac Cardiovascular Surg. 2002; 124:1248-9.

3. Schroeyers P, Coddens J, Vermeulen Y, Vanermen H. Video-assisted Port-Access aortic valve exploration through left atriotomy. Eur J Cardiothorac Surg. 2001;20:1032.

4. Chauvaud S, Fuzellier J, Berrebi A, Deloche A, Fabiani J, Carpentier A. Long-term (29 years) results of reconstructive surgery in rheumatic mitral valve insufficiency. Circulation. 2001;104(suppl I):12-5.

\section{Neonatal stenotic Ebstein's anomaly: A novel technique of right ventricular exclusion}

Tae-Jin Yun, MD, PhD, Seung-Hyun Lee, MD, and Jae-Kon Ko, MD, PhD, Seoul, Korea

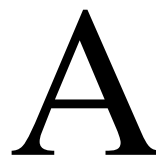

16-day-old baby with stenotic Ebstein's anomaly underwent an emergency operation to relieve progressive hypoxia, which was unresponsive to prostaglandin $\mathrm{E}_{1}$ infusion and nitric oxide inhalation. Preoperative cardiac magnetic resonance imaging showed severe enlargement of the right cardiac chambers compressing the bilateral lungs (Figure 1). Operative findings showed a hugely dilated right atrium; a large, thin-walled atrialized right ventricle (aRV); and normal size and branching pattern of the pulmonary arteries. After aortic and bicaval cannulation through a median sternotomy, the ductus was divided, and cardioplegic solution was

\footnotetext{
From the Division of Pediatric Cardiac Surgery, Asan Medical Center, College of Medicine, University of Ulsan, Seoul, Korea.

Received for publication Sept 9, 2005; accepted for publication Sept 15, 2005 .

Address for reprints: Tae-Jin Yun, MD, Division of Pediatric Cardiac Surgery, Asan Medical Center, 388-1 Poongnap-Dong, Songpa-Ku, Seoul, Republic of Korea, 138-736 (E-mail: tjyun@amc.seoul.kr).

J Thorac Cardiovasc Surg 2006;131:469-71

$0022-5223 / \$ 32.00$

Copyright (C) 2006 by The American Association for Thoracic Surgery doi:10.1016/j.jtcvs.2005.09.027
}

administered. Septal and posterior leaflets of the tricuspid valve were distally displaced down to the right ventricular outflow tract. The anterior leaflet was adherent to the right ventricular anterior free wall, leaving a small functional right

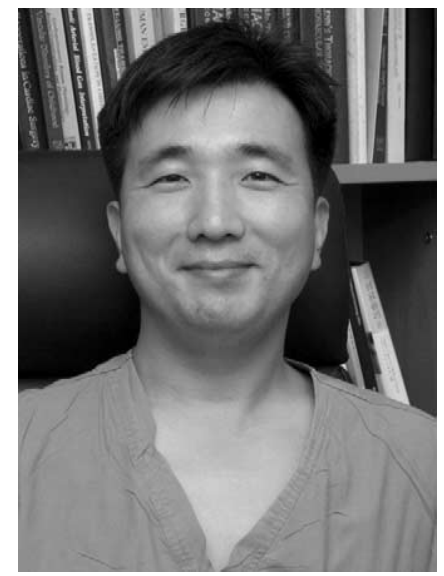

Dr Yun ventricle (fRV) in the right ventricular outflow tract. There was a small opening $(5 \mathrm{~mm}$ in diameter), or displaced tricuspid valve mechanism, between the aRV and the fRV. Given the severe wall thinning of the aRV and the small-sized fRV, biventricular repair was deemed unattainable. After the atrial septum was widely excised, the pulmonary and tricuspid valves were closed primarily. The tricuspid sac was suture obliterated from the apex to the base by suturing the right ventricular free wall to the septum, leaving the area $10 \mathrm{~mm}$ apart from the membranous septum to avoid injury of the conduction pathway (Figure 2). Once the right atrium was closed and the heart was reperfused, a $3.5-\mathrm{mm}$ polytetrafluoroethylene vascular graft was interposed between the innominate artery and the main pulmonary artery. Cardiopulmonary bypass and aortic crossclamping times were 192 minutes and 71 minutes, respectively. The baby was extubated 